\title{
Invited Commentary: Dual Coverage of the Inferior Pole with Conjoined Fascial Flap and Acellular Dermal Matrix for Immediate One-Stage Breast Reconstruction with a Prosthetic Implant
}

\author{
Bianca Knoll ${ }^{1}$ (D)
}

Received: 12 June 2018/ Accepted: 13 June 2018/Published online: 26 June 2018

(C) Springer Science+Business Media, LLC, part of Springer Nature and International Society of Aesthetic Plastic Surgery 2018

Level of Evidence $V$ This journal requires that authors assign a level of evidence to each article. For a full description of these Evidence-Based Medicine ratings, please refer to the Table of Contents or the online Instructions to Authors www.springer.com/00266.

First, the authors should be congratulated for their aesthetic outcome after breast reconstruction. The described surgical approach achieves, in a select group of patients, results that are much more related to an aesthetic procedure than reconstructive. The scars are limited, the donor site does not require an additional incision, and their technique considers the natural shape and demeanor of a breast. A fast recovery and passing the "cancer" parcours, combined with scars being more related and consistent with an aesthetic procedure, may add to the overall healing process and well-being of women who have just been confronted with a life-changing diagnosis [1-3].

The authors present a technique of lower pole support in immediate breast reconstruction in 20 Asian patients. The patients were diagnosed with breast cancer. The patients qualified oncologically for a skin-sparing mastectomy and an immediate implant breast reconstruction. Patients who are considered to be candidates for radiotherapy or chemotherapy were excluded.

The authors combine the usage of a human-derived ADM and a conjoined fascial flap (conjoined fascia of the pectoralis major, serratus anterior, and external oblique muscle). The human-derived ADM covers about $2 / 3$ of the inferomedial part of the lower pole reconstruction, whereas

Bianca Knoll

Frankfurt, Germany the conjoined fascial flap covers the remaining inferolateral portion.

The outcomes were measured using two different questionnaires. Patients reported their outcome by answering a questionnaire related to their overall satisfaction with their breast, physical, psychosocial, and sexual well-being. Two surgeons independently graded the outcomes (photographs) regarding breast symmetry, volume, breast contour, and scar appearance. The validity of their results is limited due to sample size and missing statistical analysis. Although the authors assess the outcomes from a patient and surgeon perspective, the authors do not mention whether the evaluating surgeons were the operating surgeons.

The authors argue that their technique is lowering costs and allowing a more pliable shape of the inferolateral pole of the breast. The authors state that by combining a smaller ADM with the conjoined fascial flap reduce costs, mainly because of the smaller piece of ADM.

Depending on the location of the surgical facility, the clinical setting and heath care environment may defer from the one of the authors. The additional costs related to OR time, harvesting the conjoined fascial flap, potential additional costs related to complications like seroma, bleeding, may outweigh easily the fees of using a larger ADM. Although recognized by the authors, no further details are provided. The authors do not discuss their complication rate to the existing literature.

However, the authors should be congratulated on their excellent results by introducing an additional surgical technique of lower pole reconstruction in the immediate one-stage implant reconstruction. Although this technique may not be feasible for every patient, and every clinical 
setting, the technique presents an additional valuable option and potential life boat during surgery [4].

\section{Compliance with Ethical Standards}

Conflict of interest The author declares that she has no conflicts of interest.

\section{References}

1. Pusic AL, Matros E, Fine N, Buchel E, Gordillo GM, Hamill JB, Kim HM, Qi J, Albornoz C, Klassen AF, Wilkins EG (2017) Patient-reported outcomes 1 year after immediate breast reconstruction: results of the mastectomy reconstruction outcomes consortium study. J Clin Oncol 35(22):2499-2506
2. Zhong T, Hu J, Bagher S, Vo A, O’Neill AC, Butler K, Novak CB, Hofer SO, Metcalfe KA (2016) A comparison of psychological response, body image, sexuality, and quality of life between immediate and delayed autologous tissue breast reconstruction: a prospective long-term outcome study. Plast Reconstr Surg 138(4):772-780

3. Srinivasa DR, Garvey PB, Qi J, Hamill JB, Kim HM, Pusic AL, Kronowitz SJ, Wilkins EG, Butler CE, Clemens MW (2017) Direct-to-implant versus two-stage tissue expander/implant reconstruction: 2-year risks and patient-reported outcomes from a prospective, multicenter study. Plast Reconstr Surg 140(5):869-877

4. Millard R (1986) Principle 17. Make a plan, a pattern, and a second plan (lifeboat). In: Millard R (ed) Principlization of plastic surgery. Little Brown and Company, Boston, pp 253-271 